Report

\title{
Report of the Working Group for Dietary Salt Reduction of the Japanese Society of Hypertension: (1) Rationale for Salt Restriction and Salt-Restriction Target Level for the Management of Hypertension
}

\author{
Yuhei KAWANO ${ }^{1)}$, Katsuyuki ANDO ${ }^{2)}$, Hideo MATSUURA ${ }^{3)}$, Takuya TSUCHIHASHI ${ }^{4}$, \\ Toshiro FUJITA ${ }^{2)}$, and Hirotsugu UESHIMA ${ }^{5)}$
}

\begin{abstract}
Salt excess is well known to be involved in the pathophysiology of hypertension, and thus restriction of salt intake is widely recommended for management of the disease. Excessive salt intake induces blood pressure (BP)-dependent as well as -independent progression of cardiovascular disease. Although the human body is considered to be adapted to very low salt intake (0.5-3 g/day), restriction to such a low level of salt intake is extremely difficult to accomplish in developed countries. Significant BP reduction has been reported in large-scale clinical studies in which salt intake was decreased to less than $6 \mathrm{~g} / \mathrm{day}$, and the results of a meta-analysis have shown that systolic BP was reduced about $1 \mathrm{mmHg}$ with every decrease in salt intake of $1 \mathrm{~g} /$ day in hypertensive subjects. Current guidelines for the treatment of hypertension, including Japanese guidelines, recommend dietary salt reduction to $6 \mathrm{~g} /$ day or less in hypertensive patients. However, it appears to be fairly difficult to attain this target of salt intake, especially in Japan. There is thus a need for feasible and effective measures to attain this salt restriction target. (Hypertens Res 2007; 30: 879-886)
\end{abstract}

Key Words: dietary salt, hypertension, cardiovascular disease, guidelines, large-scale clinical study

\section{Introduction}

Salt excess is well known to be involved in the pathophysiology of hypertension, and thus restriction of salt intake is widely recommended for management of the disease. Treatment guidelines for hypertension in Western countries recommend salt restriction to $6 \mathrm{~g} /$ day (sodium $[\mathrm{Na}] 100 \mathrm{mmol} /$ day) or less for hypertensives $(1,2)$. Because salt intake is higher in Japan than in Western countries, the 2000 version of the
Guidelines for the Management of Hypertension (JSH 2000) from the Japanese Society of Hypertension (JSH) set the target of salt intake at $7 \mathrm{~g} /$ day or less (3). However, the target was revised to less than $6 \mathrm{~g}$ /day in the new Japanese guidelines (2004 version: JSH 2004) (4). To promote salt restriction for the management of hypertension, the JSH organized the Working Group for Dietary Salt Reduction in 2005. In this report, we summarize the rationale for restricting salt intake for the management of hypertension. The Japanese version of the working group report has been published previously (5).

From the ${ }^{1)}$ Division of Hypertension and Nephrology, Department of Medicine, National Cardiovascular Center, Suita, Japan; ${ }^{2)}$ Department of Internal Medicine, Faculty of Medicine, University of Tokyo, Tokyo, Japan; ${ }^{3}$ Department of Internal Medicine, Saiseikai Kure Hospital, Kure, Japan; ${ }^{4}$ Division of Hypertension, National Kyushu Medical Center, Fukuoka, Japan; and ${ }^{5}$ Department of Health Science, Shiga University of Medical Science, Otsu, Japan.

Address for Reprints: Yuhei Kawano, M.D., Ph.D., Division of Hypertension and Nephrology, Department of Medicine, National Cardiovascular Center, 5-7-1 Fujishirodai, Suita 565-8565, Japan. E-mail: ykawano@hsp.ncvc.go.jp

Received June 5, 2007; Accepted in revised form August 8, 2007. 


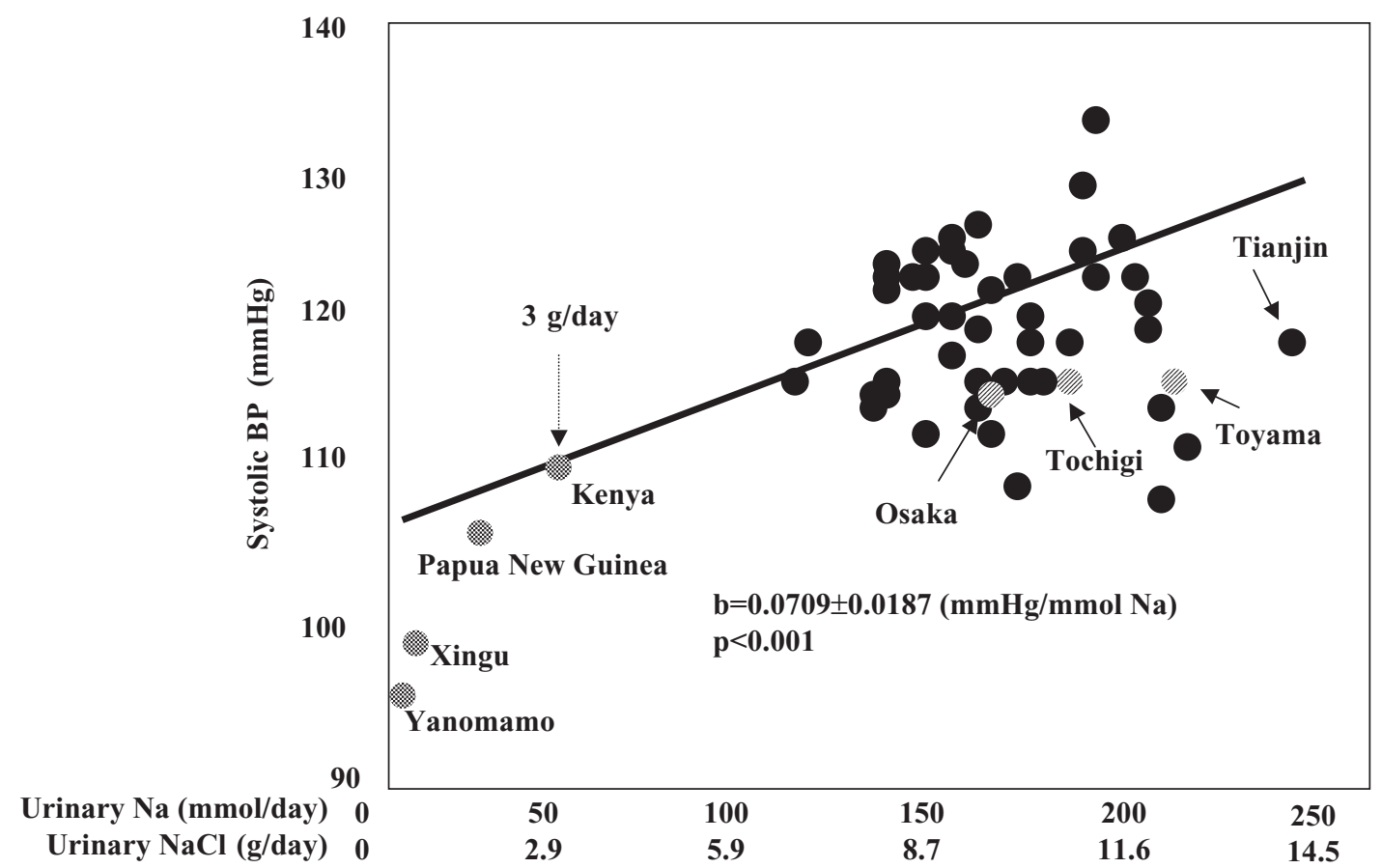

Fig. 1. Relationship between salt intake and systolic blood pressure (BP) (from Intersalt Cooperative Research Group (8) with modification).

\section{Historical Background and Current Status of Salt Intake}

Many land-dwelling animal species have difficulty gaining free access to salt and an innate salt appetite. In humans, low availability of salt has been a problem for millennia, and the period in which they could consume a large amount of salt has been very short in the history of mankind. It is estimated that humans in the Stone Age consumed salt at only 0.5-3 g/day (6), and the human body is considered to be adapted to such low salt intake. Physiologic studies have also suggested that the minimum salt requirement for human survival is about 0.5 g/day (7).

The amount of salt intake in humans shows wide regional and individual variations. The international cooperative Intersalt study, which investigated salt intake and blood pressure (BP) in various parts of the world, reported that salt intake ranged from less than $0.1 \mathrm{~g} /$ day in Yanomano, South America to about $15 \mathrm{~g} /$ day in Tianjin, China (8) (Fig. 1). Generally, salt intake is low in undeveloped regions and high in developed countries.

In Japan, the salt intake was traditionally high, especially in the Tohoku District (about $25 \mathrm{~g}$ /day in the 1950s) (3). Although the amount of salt consumption in Japanese has considerably decreased, the intake remains high, at about 11 g/day (9) (Fig. 2). Therefore, even today, most Japanese are consuming about 10 times the required amount of salt. In hypertensive patients treated on an outpatient basis, the mean salt intake estimated from the urinary $\mathrm{Na}$ excretion has also been reported to be high, at about $11 \mathrm{~g}$ /day (10) or $10 \mathrm{~g}$ /day (11). Salt intake is slightly higher in males than in females $(9$, 11). Since this gender difference disappears when the values are corrected for body weight, it is considered to be ascribable to gender-related differences in physique (11).

\section{Effects of Excessive Salt Intake}

\section{Hypertension}

Many epidemiological, experimental, and clinical studies have clearly indicated that excessive salt intake is related to increases in BP and the progression of hypertension (12). For example, the Intersalt study found that salt intake was significantly correlated with BP; BP was extremely low particularly in groups with very low (less than $3 \mathrm{~g}$ /day) salt intake $(8,13)$ (Fig. 1, Table 1). Moreover, little age-associated increase in BP was noted in these groups. Therefore, salt intake of less than $3 \mathrm{~g}$ /day is considered to be ideal for the prevention or treatment of hypertension.

Experimentally, the intake of excessive salt has been shown to induce or exacerbate hypertension in many models, including Dahl salt-sensitive rats and deoxycorticosterone acetate (DOCA)-salt hypertensive rats. Although the mechanism by which salt increases BP has not been completely elucidated, the kidney is considered to play an important role. The central 


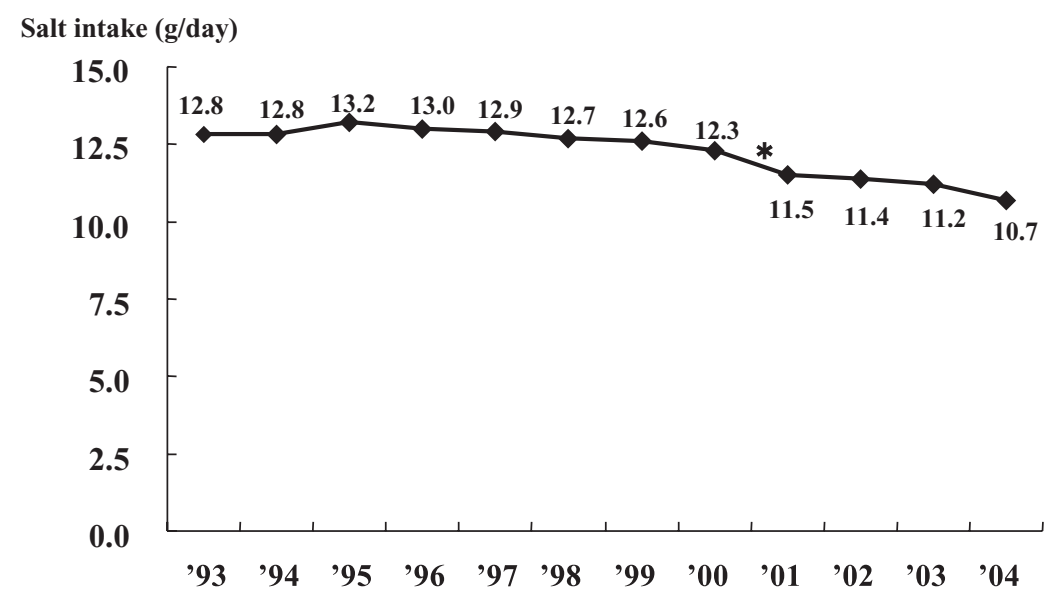

Fig. 2. Trend of daily salt intake in Japan (based on data of Lifestyle-Related Disease Control Section, General Affairs Division, Health Bureau, Ministry of Health, Labor and Welfare (9)). *Calculated on the basis of the 4th edition of the Standard Tables of Food Composition in Japan until 2000 and 5th edition after 2001.

Table 1. Comparison of Low Salt Intake Groups with Other Groups-Intersalt Study*

\begin{tabular}{|c|c|c|c|c|c|}
\hline & Yanomamo & Xingu & Papua New Guinea & Kenya & Others $(n=48)$ \\
\hline \multicolumn{6}{|l|}{ Lifestyle } \\
\hline Salt intake (g/day) & $<0.06$ & 0.35 & 1.6 & 3.0 & 9.4 \\
\hline $\mathrm{Na} / \mathrm{K}$ ratio & $<0.01$ & 0.08 & 0.48 & 1.8 & 3.4 \\
\hline BMI $\left(\mathrm{kg} / \mathrm{m}^{2}\right)$ & 21.2 & 23.4 & 21.7 & 20.8 & 25.2 \\
\hline Regular drinkers (\%) & 0 & 0 & 8.7 & 30.7 & 53.0 \\
\hline \multicolumn{6}{|l|}{ Bood pressure } \\
\hline Systolic BP (mmHg) & 95.4 & 98.9 & 107.7 & 109.9 & 118.7 \\
\hline Diastolic BP (mmHg) & 61.4 & 61.7 & 62.9 & 67.9 & 74.0 \\
\hline Hypertensives (\%) & 0 & 1.0 & 0.8 & 5.0 & 17.4 \\
\hline Age-associated increases in BP (mmHg/10 years) & -1.1 & +0.6 & -1.4 & +2.4 & +5.0 \\
\hline
\end{tabular}

*From Stamler et al. (13) with permission. $\mathrm{Na} / \mathrm{K}$ ratio, sodium/potassium ratio; BMI, body mass index; BP, blood pressure.

nervous system, various neurohumoral factors, and vasoactive substances may also be involved (12).

Many clinical reports have suggested that BP is increased by excessive salt intake. However, the increase in BP due to excessive salt intake varies widely among individuals, and many people remain normotensive even on a high-salt diet. In fact, hypertensives can be classified into salt-sensitive and non-salt-sensitive groups, because the responses of BP to a high-salt or low-salt diet are not uniform $(14,15)$. Many factors, including genetic interference, renal function, and neurohumoral elements, are involved in the salt sensitivity of BP.

\section{Cardiovascular Diseases}

Salt excess is related to the occurrence and progression of cardiovascular diseases through its BP-increasing effects, but it has also been shown that salt exerts adverse effects on the cardiovascular system by different mechanisms in addition to rise in BP (16) (Table 2). Excessive salt intake causes left ventricular hypertrophy and thickening of the vascular wall independently of its effects on BP. According to a report from Finland, mortality from ischemic heart disease, stroke and all causes increased significantly with increases in salt intake even after correction for BP or other factors (17) (Table 3). Furthermore, salt intake has been shown to be an independent risk factor of stroke and heart failure $(18,19)$. Dietary salt may also relate to impairment of platelet aggregation and renal function (15), so that salt excess is considered to confer a greater risk of cardiovascular diseases than would be expected by a mere increase in BP.

\section{Other Disorders}

Excessive salt intake is also related to several other disorders (16) (Table 2). An increase in salt intake elevates the urinary calcium $(\mathrm{Ca})$ excretion and the incidence of urolithiasis. This loss of $\mathrm{Ca}$ through the kidney also decreases $\mathrm{Ca}$ in the bone and increases the risk of osteoporosis. Moreover, a relation- 
Table 2. Adverse Effects of Salt Independent of BP

Cardiovascular system
Left ventricular hypertrophy
Thickening/hardening of vascular wall
Platelet aggregation
Cardiovascular disorders
Stroke
Ischemic heart disease, Heart failure
Impairment of renal function
Other disorders
Urolithiasis
Osteoporosis
Stomach cancer
Asthma

ship between salt intake and stomach cancer has been suggested by epidemiological studies. A high-salt environment has recently been reported to promote the propagation of Helicobacter pyroli. A relationship between salt intake and asthma has also been suspected. Thus, excessive salt intake is considered to exert various adverse effects.

\section{Antihypertensive Effect of Salt Restriction}

There is much evidence based on clinical studies that restriction of salt intake reduces BP in hypertensives. In Japan, Ito et al. reported the results of moderate restriction of salt intake in a small number of subjects. Blood pressure decreased slightly but not significantly when salt intake was reduced from $13 \mathrm{~g} /$ day to $7 \mathrm{~g}$ /day but significantly when it was rigorously restricted to $3 \mathrm{~g} /$ day (20). All large-scale clinical studies to date have been performed in Europe or America. Significant decreases in BP were observed in the Trials of Hypertension Prevention (TOHP)-Phase I (TOHP-I) (21), the Trial of Nonpharmacologic Interventions in the Elderly (TONE) (22), a report from He et al. (23), and the Dietary Approaches to Stop Hypertension (DASH)-Sodium trial (24), in all of which salt intake was reduced to less than $6 \mathrm{~g}$ /day (Table 4). But the decreases were not significant in the TOHP-II study (25), in which restriction of salt intake was milder. In the Hypertension Prevention Trial (HPT), salt intake was reduced to less than $6 \mathrm{~g}$ /day, but no significant decrease in BP was observed, probably because salt intake was also decreased in the control group (26). In the TONE, evaluations were also performed at various levels of salt restriction achieved, and salt intake to $5.64 \mathrm{~g} /$ day or less was effective for the maintenance of a normal BP after discontinuation of antihypertensive medication (22). On the basis of these results, many guidelines for the management of hypertension in Western countries recommend less than $6 \mathrm{~g}$ /day as a target for salt restriction $(1,2)$.

According to a meta-analysis of randomized studies on the effect of moderate salt restriction, BP decreased by a mean of 5.0/2.7 $\mathrm{mmHg}$ in hypertensive subjects (27) (Fig. 3). The
Table 3. Hazard Ratios and $95 \%$ CI of Deaths Due to Ischemic Heart Disease, Stroke, and All Causes Associated with Increases in the Urinary Na Excretion (100 mmol/day) after Adjustment*

\begin{tabular}{lc}
\hline \multicolumn{1}{c}{ Cause of death } & Hazard ratio $(95 \% \mathrm{CI})$ \\
\hline Ischemic heart disease & $1.56(1.15-2.12)$ \\
Stroke & $1.36(1.05-1.76)$ \\
All causes & $1.22(1.02-1.47)$ \\
\hline
\end{tabular}

*From Tumilehto et al. (17) with modification. CI, confidence interval; BP, blood pressure.

median urinary $\mathrm{Na}$ excretion was $161 \mathrm{mmol} /$ day (conversion to salt: $9.5 \mathrm{~g} /$ day) on an unrestricted diet and $87 \mathrm{mmol} /$ day $(5.1 \mathrm{~g} /$ day $)$ on a low-salt diet, with a median decrease in the urinary $\mathrm{Na}$ excretion of $78 \mathrm{mmol} /$ day (4.6 g/day). In normotensive subjects, the mean decrease in $\mathrm{BP}$ was $2.0 / 1.0 \mathrm{mmHg}$, and the decrease in the urinary $\mathrm{Na}$ excretion was $74 \mathrm{mmol} /$ day ( $4.4 \mathrm{~g} /$ day). A recent analysis showed a clear quantitative relationship between the degree of decrease in salt intake and $\mathrm{BP}$ in a salt intake range of 3-12 g/day (27). In hypertensives, the systolic BP is considered to decrease by about $1 \mathrm{mmHg}$ with each decrease in salt intake of $1 \mathrm{~g}$ /day. If a person who has consumed salt at $12 \mathrm{~g}$ /day restricts salt intake to $6 \mathrm{~g} /$ day, a considerable decrease in BP is expected with a consequent decrease in the dose of antihypertensive medication and prevention of cardiovascular diseases.

There have been no large-scale clinical studies about the effects of salt reduction on BP in Japan. However, many short-term clinical studies have shown that the restriction of salt intake effectively lowers BP in hypertensive Japanese $(20,28-31)$. The average reduction in mean BP with a lowsalt diet in those studies was $5-10 \mathrm{mmHg}$, which was comparable to the results of a meta-analysis. It has been shown that there is a racial difference in the salt sensitivity of BP, with the sensitivity in blacks being greater than that in whites (32). Although there are no studies directly comparing the salt sensitivity among Japanese and other races, the salt sensitivity of BP in Japanese may be intermediate between those of blacks and whites.

However, the responses of BP to a decrease in salt intake show marked individual variation. The depressor effect of reduction in salt intake has been shown to be large in the elderly, patients with renal dysfunction, those with severe hypertension, and those with low-renin hypertension $(28,32)$. However, because hypertension arises through the intricate interplay of many factors, it is not easy to predict the salt sensitivity of BP in individual patients, and evidence is not sufficient to warrant individualized recommendations of salt restriction.

Decreases in BP due to salt restriction are observed $24 \mathrm{~h}$ a day (29). Also, it has been reported that many salt-sensitive hypertensives are non-dippers, who show only small nocturnal decreases in BP, on a high-salt diet, but become dippers 


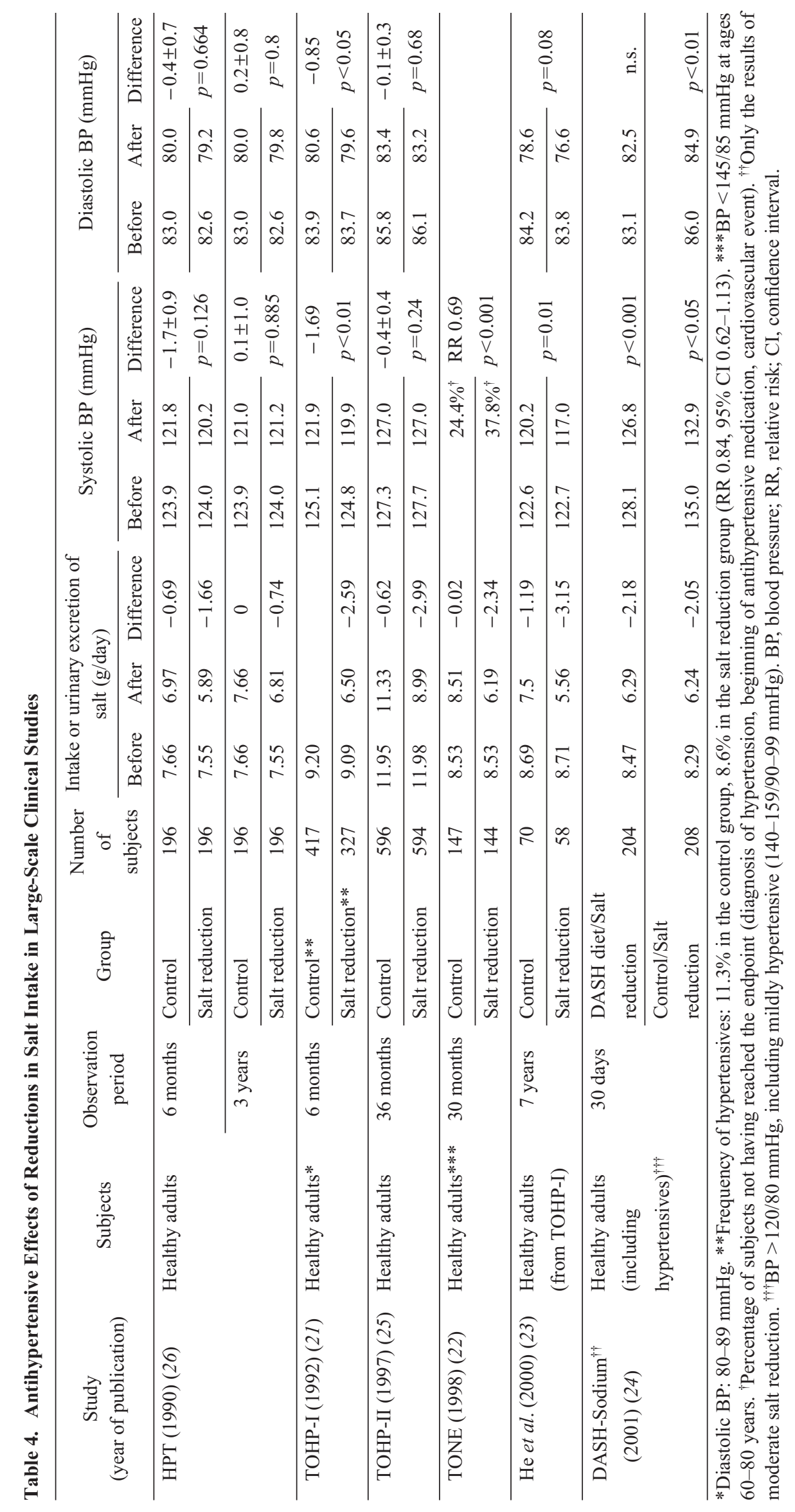




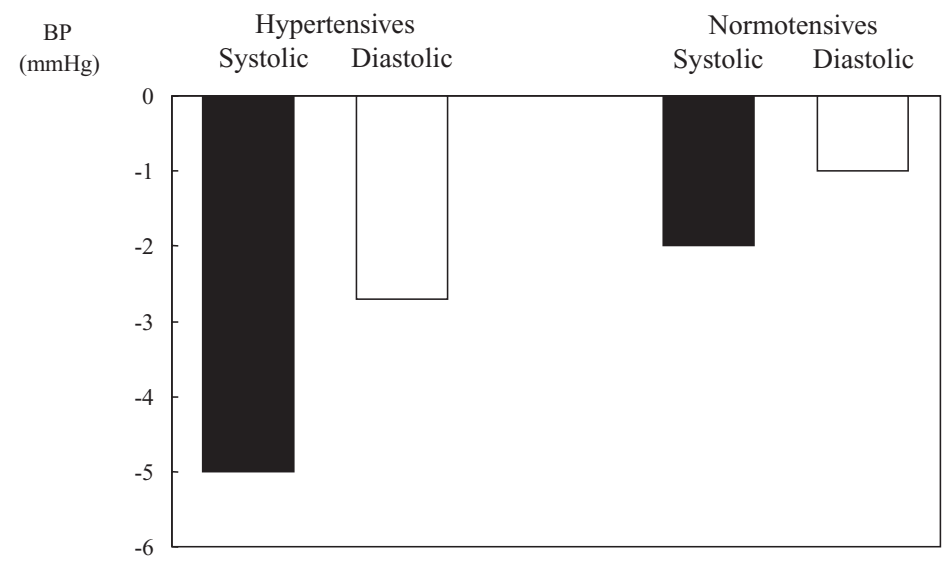

Fig. 3. Effects of moderate salt reduction on BP according to a meta-analysis of randomized clinical trials (based on data of He et al. (27)).

Table 5. Salt Reduction Accomplishment Rate in the TONE Study*

\begin{tabular}{lcc}
\hline \multicolumn{1}{c}{ Salt reduction level } & $<5.6 \mathrm{~g} /$ day & $>7.1 \mathrm{~g} /$ day \\
\hline Control group & $15.3 \%$ & $67.7 \%$ \\
Salt reduction group & $51.2 \%$ & $29.7 \%$ \\
Weight control group & $6.1 \%$ & $79.6 \%$ \\
Salt reduction+weight control group & $23.8 \%$ & $49.0 \%$ \\
\hline
\end{tabular}

*From Espeland et al. (36) with modification.

with salt restriction (31).

Dietary intakes of potassium and sodium interact in the regulation of BP (33). Increasing potassium intake decreases BP mainly via natriuresis, and increasing sodium intake stimulates potassium excretion. A high potassium diet accomplished by means of fruit and vegetable intake is now widely recommended in the management of hypertension $(1,2,4)$. The DASH-Sodium study has shown that a DASH (high potassium) diet and sodium restriction additively lower BP, but the effect of sodium restriction was greater under a normal diet than under the DASH diet (24). Thus a low sodium, high potassium diet is suitable for hypertensive subjects, but the BP-lowering effect of salt reduction appears to be attenuated by increasing potassium intake.

Restriction of salt intake also enhances the effects of some antihypertensive agents. This effect is particularly evident in inhibitors of the renin-angiotensin system. Sympatholytic agents are also expected to have similar effects.

An improvement of cardiovascular disease outcome can be expected with long-term restriction of sodium intake. The follow-up study of the TOHP-I and -II has shown that risk of a cardiovascular event is $30 \%$ lower among participants in the intervention (sodium restriction) group compared to those in the control group after adjustment for confounding factors (34). Therefore, sodium restriction not only lowers BP but may also reduce long-term risk of cardiovascular events.

\section{Attainment and Maintenance of the Salt-Reduction}

Lifestyle modifications, including salt restriction, are extremely important for the management of hypertension, but the difficulty of attaining and maintaining such changes is a problem (35). There have been few reports on the attainment rate of salt reduction in hypertensives, but in the TONE, a trial with elderly hypertensive subjects, the target of less than 5.6 $\mathrm{g}$ /day was attained by about half of the patients in the salt reduction guidance group and about $1 / 4$ of the patients in the salt reduction plus weight control group (36) (Table 5). In Japan, in a trial in which physicians provided salt reduction guidance to hypertensives with a target of less than $6 \mathrm{~g} /$ day, mean salt intake decreased from 11.2 to $9.9 \mathrm{~g}$ /day, but the target was attained in only $12 \%$ of subjects $(10,35)$. Also, while salt intake was lower in hypertensives intending to reduce salt intake than in those not intending, it was 9.4 and $10.6 \mathrm{~g} /$ day, respectively, with a minor difference (11). According to a report of the International Population Study on Macronutrients and Blood Pressure (INTERMAP), in Japanese subjects, among those practicing salt reduction, only $41.6 \%$ attained a target of less than $10 \mathrm{~g} /$ day, and the average salt intake estimated from the urinary $\mathrm{Na}$ excretion was $10.5 \mathrm{~g} /$ day (37). Therefore, attainment of the target of less than $6 \mathrm{~g} /$ day appears to be fairly difficult.

Limitations of long-term compliance to salt restriction and its effects have also been demonstrated. In the Treatment of Mild Hypertension Study (TOMHS), which provided 4-year lifestyle guidance to mildly hypertensive subjects, salt intake decreased by $2-3 \mathrm{~g} /$ day during the first year, but the decrease regressed to less than $1 \mathrm{~g}$ /day after 4 years (38). Moreover, a meta-analysis of long-term randomized interventional studies of 6 months or longer duration in normotensive and hyperten- 
sive subjects showed that the mean decrease in salt intake was $2.1 \mathrm{~g} /$ day, and the mean decrease in BP was only 1.1/0.6 mmHg (39).

\section{Salt-Reduction Target for the Management of Hypertension}

Dietary salt appears to be related to hypertension, and excessive salt intake exerts adverse effects on the cardiovascular system independently of BP. While the antihypertensive effect of salt restriction is dependent on the degree of salt reduction, significant depressor effects have been confirmed at restriction levels of $6 \mathrm{~g}$ /day or less in large-scale clinical trials. Therefore, for the management of hypertension, the target of salt reduction should ideally be less than $6 \mathrm{~g}$ /day as in Western guidelines. In Japan, the target of salt reduction was set at $7 \mathrm{~g}$ /day or less in JSH 2000 (3) because of the traditionally high salt intake, but salt intake of Japanese has since decreased by about $1 \mathrm{~g} /$ day, so that it was considered reasonable to reset the target to less than $6 \mathrm{~g}$ /day in the subsequent JSH 2004 guidelines (4).

Presently, it appears to be difficult to attain the target of less than $6 \mathrm{~g}$ /day, but promotion of nationwide educational activities about the importance of the prevention and treatment of hypertension by salt restriction and its considerable preventive effect against cardiovascular and other diseases is considered to be a socially, economically, and medically important task. The establishment of feasible and effective measures by multi-faceted approaches is desirable for the attainment of the target of salt reduction.

\section{Conclusions}

Excessive salt intake is closely related to the occurrence and progression of hypertension, and it also exerts adverse effects on the cardiovascular system independently of BP. The depressor effect of salt restriction is dose-dependent, and despite marked individual variation, BP has been shown to decrease about $1 \mathrm{mmHg}$ on average with each decrease in salt intake of $1 \mathrm{~g} /$ day. Salt reduction is important for the prevention and treatment of hypertension, and there is reasonable evidence in support of the current salt-restriction target of less than $6 \mathrm{~g} /$ day $(\mathrm{Na}<100 \mathrm{mmol} /$ day $)$. Salt reduction is particularly important in Japan, a country with high salt intake, but attaining the new target has proven difficult in Japanese hypertensives. There is thus a need to establish new effective measures for attaining the target.

\section{References}

1. Chobanian AV, Bakris GL, Black HR, et al: The seventh report of the Joint National Committee on Prevention, Detection, Evaluation, and Treatment of High Blood Pressure: the JNC-7 report. JAMA 2003; 289: 2560-2572.

2. Guidelines Committee: 2003 European Society of Hyper-
tension-European Society of Cardiology guidelines for the management of arterial hypertension. J Hypertens 2003; 21: 1011-1053.

3. Japanese Society of Hypertension Guidelines Subcommittee for the Management of Hypertension: Guidelines for the Management of Hypertension for General Practitioners. Hypertens Res 2001; 24: 613-634.

4. Japanese Society of Hypertension: Japanese Society of Hypertension Guidelines for the Management of Hypertension (JSH 2004). Hypertens Res 2006; 29 (Suppl): S1S105.

5. Kawano Y, Ando K, Matsuura H, Tsuchihashi T, Fujita T, Ueshima $\mathrm{H}$ : Rationale of salt restriction and its target for the management of hypertension, in Report of the Working Group for Dietary Salt Reduction of the Japanese Society of Hypertension. Tokyo, Japanese Society of Hypertension, 2006, pp 1-12 (in Japanese).

6. Eaton SB, Eaton SB 3rd, Konner MJ, et al: An evolutionary perspective enhances understanding of human nutritional requirement. J Nutr 1996; 126: 1732-1740.

7. Dahl LK: Salt intake and salt need. N Engl J Med 1958; 258: 1205-1208.

8. Intersalt Cooperative Research Group: Intersalt: an international study of electrolyte excretion and blood pressure: results for 24 hour urinary sodium and potassium excretion. BMJ 1988; 297: 319-328.

9. Lifestyle-Related Disease Control Section, General Affairs Division, Health Bureau, Ministry of Health, Labor and Welfare: An outline of the results of the 2004 National Health and Nutrition Survey (in Japanese). http:// www.mhlw.go.jp/houdou/2006/05/h0508-1a.html

10. Kawano Y, Minami J, and Takishita S: Evaluation of the effects of mineral intake in hypertensive patients by blood pressure monitoring: combination of $\mathrm{K}, \mathrm{Ca}$, and $\mathrm{Mg}$ supplementation and Na restriction. Ther Res 1998; 19: 15171520 (in Japanese).

11. Ohta $\mathrm{Y}$, Tsuchihashi $\mathrm{T}$, Ueno $\mathrm{M}$, et al: Relationship between the awareness of salt restriction and the actual salt intake in hypertensive patients. Hypertens Res 2004; 27: 243-246.

12. Fujita $\mathrm{T}$ (ed): Salt and Hypertension. Tokyo, Nihon Igaku Shuppan, 2002 (in Japanese).

13. Stamler J, Rose G, Elliott P, et al: Findings of the international cooperative INTERSALT study. Hypertension 1991; 17 (Suppl 1): I-9-I-15.

14. Kawasaki T, Delea CS, Bartter FC, et al: The effect of highsodium and low-sodium intakes on blood pressure and other related variables in human subjects with idiopathic hypertension. Am J Med 1978; 64: 193-198.

15. Fujita T, Ando K, Ogata E: Systemic and regional hemodynamics in patients with salt-sensitive hypertension. Hypertension 1990; 16: 235-244.

16. de Wardener HE, MacGregor GA: Harmful effects of dietary salt in addition to hypertension. J Hum Hypertens 2002; 16: 213-223.

17. Tumilehto J, Jousilahti $\mathrm{P}$, Rastenyte $\mathrm{D}$, et al: Urinary sodium excretion and cardiovascular mortality in Finland: a prospective study. Lancet 2001; 357: 848-851.

18. Nagata C, Takatsuka N, Shimizu N, et al: Salt intake and risk of death from stroke in Japanese men and women. 
Stroke 2004; 35: 1543-1547.

19. He J, Ogden LG, Bazzano LA, et al: Dietary sodium intake and incidence of congestive heart failure in overweight US men and women: First National Health and Nutrition Examination Survey Epidemic Follow-up study. Arch Intern Med 2002; 162: 1619-1624.

20. Ito K, Kuroda K, Tsuchiya M, et al: Gradient salt reduction and its antihypertensive effect in patients with essential hypertension. Magnesium 1982; 1: 224-231.

21. The Trials of Hypertension Prevention Collaborative Research Group: The effects of nonpharmacologic interventions on blood pressure and hypertension incidence in overweight people with high-normal blood pressure. JAMA 1992; 267: 1213-1220.

22. Whelton PK, Appel AJ, Espeland MA, et al: Sodium reduction and weight loss in the treatment of hypertension in older persons: a randomized controlled trial of nonpharmacologic interventions in the elderly (TONE). JAMA 1998; 279: 839-846.

23. He J, Whelton PK, Appel LJ, et al: Long-term effects of weight loss and dietary sodium reduction on incidence of hypertension. Hypertension 2000; 35: 544-549.

24. Sacks FM, Svetkey LP, Vollmer WM, et al: Effects on blood pressure of reduced dietary sodium and the Dietary Approaches to Stop Hypertension (DASH) diet. $N$ Engl $J$ Med 2001; 344: 3-10.

25. The Trials of Hypertension Prevention Collaborative Research Group: Effects of weight loss and sodium reduction intervention on blood pressure and hypertension incidence in overweight people with high-normal blood pressure: the Trials of Hypertension Prevention, phase II. Arch Intern Med 1997; 157: 657-667.

26. Hypertension Prevention Trial Research Group: The Hypertension Prevention Trial: three-year effects of dietary changes on blood pressure. Arch Intern Med 1990; 150: 153-162.

27. He FJ, MacGregor GA: Effect of modest salt reduction on blood pressure: a meta-analysis of randomized trials. Implications for public health. J Hum Hypertens 2002; 16: 761770 .

28. Oshima T, Matsuura H, Kido K, et al: Factors determining sodium chloride sensitivity of patients with essential hypertension: evaluation by multivariate analysis. $J$ Hypertens 1989; 7: 223-227.

29. Kawano Y, Abe H, Kojima S, et al: Different effects of alcohol and salt on 24-hour blood pressure and heart rate in hypertensive patients. Hypertens Res 1996; 19: 255-261.

30. Ando K, Takahashi K, Shimosawa T, et al: Effect of aging on salt sensitivity of blood pressure in patients with essential hypertension. Clin Exp Nephrol 1999; 1: 18-22.

31. Uzu T, Ishikawa K, Fujii K, et al: Sodium restriction shifts circadian rhythm of blood pressure from nondipper to dipper in essential hypertension. Circulation 1997; 96: 18591862.

32. Luft FC, Miller JZ, Grimm CE, et al: Salt sensitivity and resistance of blood pressure: age and race as factors in physiological responses. Hypertension 1991; 17: I-102-I-108.

33. Adrogue HJ, Madias NE: Sodium and potassium in the pathogenesis of hypertension. $N$ Engl J Med 2007; 356: 1966-1978.

34. Cook NR, Cutler JA, Obarzanek E, et al: Long term effects of dietary sodium restriction on cardiovascular disease outcomes: observational follow-up of the trials of hypertension prevention (TOHP). BMJ 2007; 334: 885-888.

35. Kawano Y, Omae T: Lifestyle modifications in the management of hypertension: effects and limitations. CVD Prevention 1998; 1: 336-346.

36. Espeland MA, Whelton PK, Kostis JB, et al: Predictors and mediators of successful long-term withdrawal from antihypertensive medications. TONE Collaborative Research Group. Trial of Nonpharmacologic Intervention in the Elderly. Arch Fam Med 1999; 8: 228-236.

37. Tsunematsu N, Ueshima H, Okuda $\mathrm{N}$, et al: The actual amount of reductions in salt intake among those on a restricted salt diet: from the INTERMAP Japan. J Jpn Soc Prev Cardiovasc Dis 2004; 39: 149-155.

38. Neaton JD, Grimm RH Jr, Prineas RJ, et al: Treatment of Mild Hypertension Study: final results. JAMA 1993; 270: 713-724.

39. Hooper L, Bartlett C, Smith GD, et al: Systematic review of long term effects of advice to reduce dietary salt in adults. BMJ 2002; 325: 628-632. 